PREPARED FOR THE U.S. DEPARTMENT OF ENERGY, UNDER CONTRACT DE-AC02-76CH03073

PPPL-3820

PPPL-3820

UC-70

\title{
Electron Bernstein Wave Research on NSTX and CDX-U
}

by

G. Taylor, P.C. Efthimion, B. Jones, G.L. Bell, A. Bers, T.S. Bigelow, M.D. Carter, R.W. Harvey, A.K. Ram, D.A. Rasmussen, A.P. Smirnov, J.B. Wilgen, and J.R. Wilson

June 2003
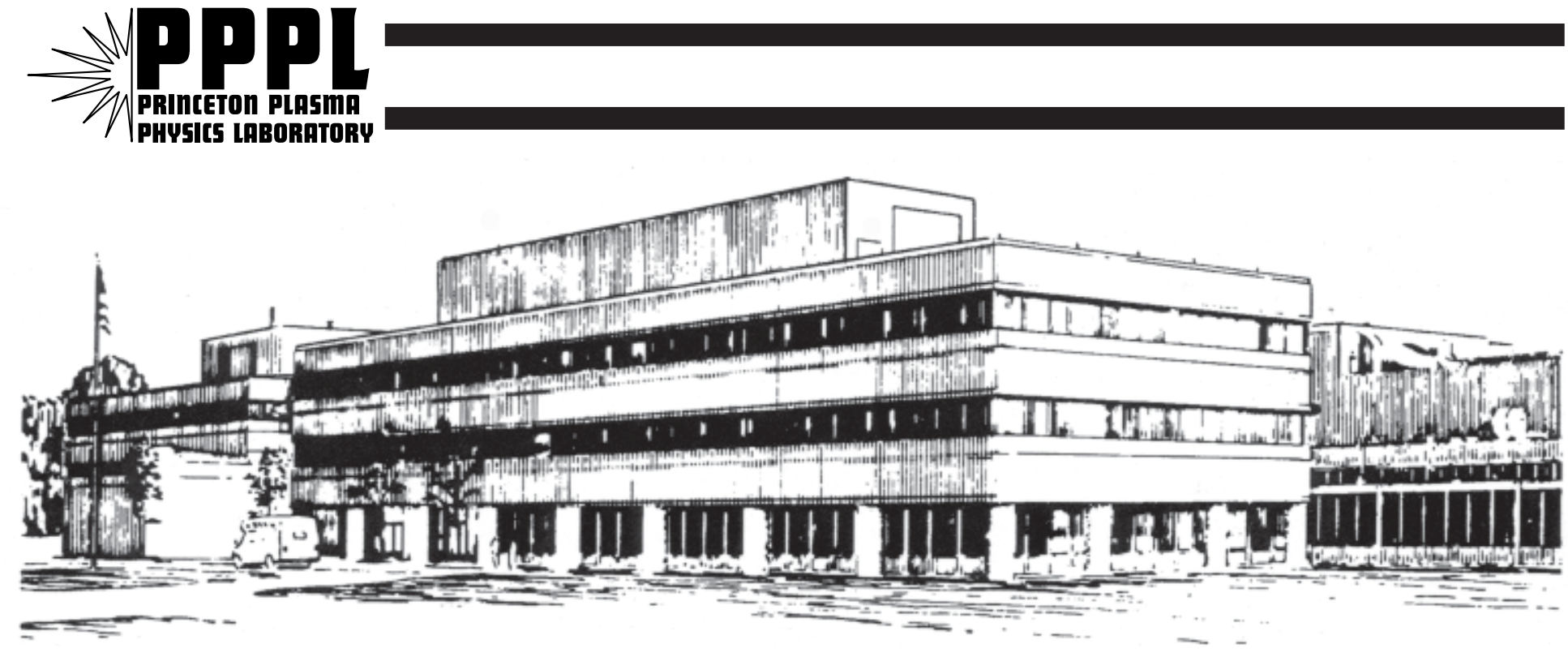

PRINCETON PLASMA PHYSICS LABORATORY PRINCETON UNIVERSITY, PRINCETON, NEW JERSEY 


\section{PPPL Reports Disclaimer}

This report was prepared as an account of work sponsored by an agency of the United States Government. Neither the United States Government nor any agency thereof, nor any of their employees, makes any warranty, express or implied, or assumes any legal liability or responsibility for the accuracy, completeness, or usefulness of any information, apparatus, product, or process disclosed, or represents that its use would not infringe privately owned rights. Reference herein to any specific commercial product, process, or service by trade name, trademark, manufacturer, or otherwise, does not necessarily constitute or imply its endorsement, recommendation, or favoring by the United States Government or any agency thereof. The views and opinions of authors expressed herein do not necessarily state or reflect those of the United States Government or any agency thereof.

\section{Availability}

This report is posted on the U.S. Department of Energy's Princeton Plasma Physics Laboratory Publications and Reports web site in Fiscal Year 2003. The home page for PPPL Reports and Publications is: http://www.pppl.gov/pub_report/

DOE and DOE Contractors can obtain copies of this report from:

U.S. Department of Energy

Office of Scientific and Technical Information

DOE Technical Information Services (DTIS)

P.O. Box 62

Oak Ridge, TN 37831

Telephone: (865) 576-8401

Fax: (865) 576-5728

Email: reports@adonis.osti.gov

This report is available to the general public from:

National Technical Information Service

U.S. Department of Commerce

5285 Port Royal Road

Springfield, VA 22161

Telephone: $1-800-553-6847$ or

(703) $605-6000$

Fax: (703) 321-8547

Internet: http://www.ntis.gov/ordering.htm 


\title{
Electron Bernstein Wave Research on NSTX and CDX-U
}

\author{
G. Taylor ${ }^{\mathrm{a}}$, P.C. Efthimion ${ }^{\mathrm{a}}$, B.Jones ${ }^{\mathrm{b}}$, G.L. Bell ${ }^{\mathrm{c}}$, A. Bers ${ }^{\mathrm{d}}$, \\ T.S. Bigelow ${ }^{\mathrm{c}}$, M.D. Carter ${ }^{\mathrm{c}}$, R.W. Harvey ${ }^{\mathrm{e}}$, A.K. Ram ${ }^{\mathrm{d}}$, \\ D.A. Rasmussen ${ }^{\mathrm{c}}$, A.P. Smirnov ${ }^{\mathrm{f}}$, J.B.Wilgen ${ }^{\mathrm{c}}$, J.R. Wilson ${ }^{\mathrm{a}}$ \\ ${ }^{a}$ Princeton University, Princeton, NJ 08543, USA \\ ${ }^{b}$ Sandia Laboratory, Albuquerque, NM 87185, USA \\ 'Oak Ridge National Laboratory, Oak Ridge, TN 37831, USA \\ ${ }^{d}$ Plasma Science and Fusion Center, Cambridge, MA 02139, USA \\ ${ }^{e}$ CompX, Del Mar, CA 92014, USA \\ ${ }^{f}$ Moscow State University, Moscow, Russia
}

\begin{abstract}
Studies of thermally emitted electron Bernstein waves (EBWs) on CDX-U and NSTX, via mode conversion (MC) to electromagnetic radiation, support the use of EBWs to measure the $T_{e}$ profile and provide local electron heating and current drive (CD) in overdense spherical torus plasmas. An X-mode antenna with radially adjustable limiters successfully controlled EBW MC on CDX-U and enhanced MC efficiency to $\sim 100 \%$. So far the X-mode MC efficiency on NSTX has been increased by a similar technique to $40-50 \%$ and future experiments are focused on achieving $\geq 80 \%$ MC. MC efficiencies on both machines agree well with theoretical predictions. Ray tracing and Fokker-Planck modeling for NSTX equilibria are being conducted to support the design of a 3 MW, $15 \mathrm{GHz}$ EBW heating and CD system for NSTX to assist non-inductive plasma startup, current ramp up, and to provide local electron heating and CD in high $\square$ NSTX plasmas.
\end{abstract}

\section{INTRODUCTION}

CDX-U [1] and NSTX [2] are high $\square$ spherical tori that contain overdense $\left(\square_{p e}>>\square_{c e}\right)$ plasmas that are not accessible to low harmonic electron cyclotron waves, and hence preclude the use of established technologies such as ECRH and ECCD. Since electron Bernstein waves (EBWs) propagate in overdense plasmas and absorb strongly at electron cyclotron resonances, they may be used for local electron temperature measurements, electron heating $(E B W H)$ and current drive (EBWCD). Coupling to EBWs is possible via mode conversion (MC) of electromagnetic waves in the vicinity of the plasma edge $[3,4]$. Recent studies of thermally emitted EBWs via MC have evaluated the EBW MC physics both to develop a local electron temperature diagnostic and, as a result of the symmetry of the MC process [5], to support the development EBWH and EBWCD.

\section{EBW MODE CONVERSION MEASUREMENTS}

Optimized EBW MC has been demonstrated on CDX-U, with almost complete conversion of thermally emitted EBWs to X-mode electromagnetic radiation, in agreement with theoretical predications using the measured density scale length $\left(L_{n}\right)$ at the MC layer [6]. A local, radially scanned, limiter surrounding a quad-ridged antenna produced controlled steepening of $L_{n}$ from $>3 \mathrm{~cm}$ to $7 \mathrm{~mm}$ in the vicinity of the EBW to X-mode MC layer, resulting in an order of magnitude increase in the $\mathrm{MC}$ efficiency of fundamental EBW emission, so that $T_{r a d} \sim T_{\mathrm{e}}$, measured by Thomson scattering (Fig. 1(a)). 
(a)

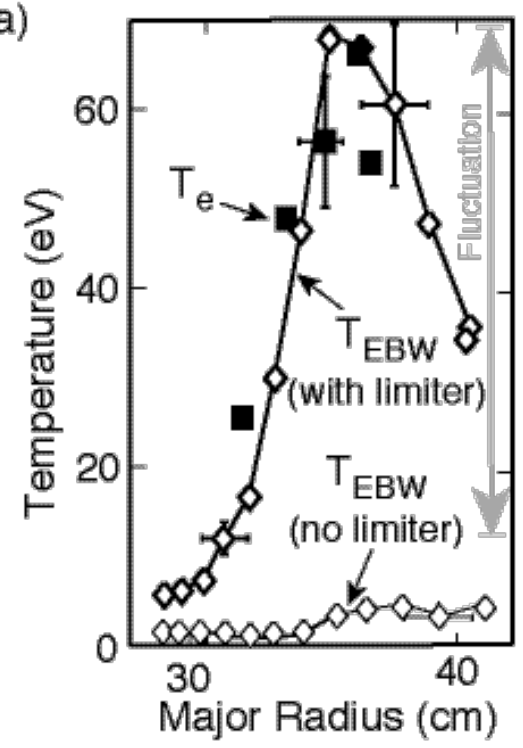

(b)

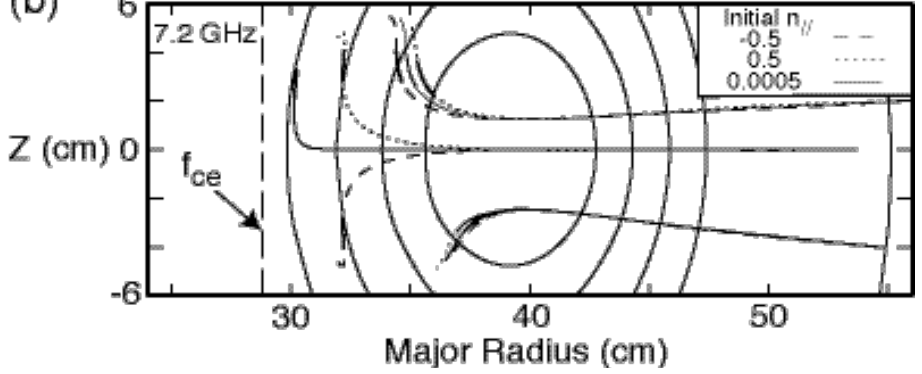

Figure 1. (a) Radiation temperature of MC EBW emission with and without a local limiter on CDX-U. When the limiter shortens $L_{n}$ to $7 \mathrm{~mm}$ at the EBW MC layer, the EBW $T_{r a d}$ and $T_{e}$ profiles are similar. The EBW $T_{\text {rad }}$ exhibits large amplitude fluctuations (vertical grey arrows). (b) GENRAY calculation showing significant displacement for EBW rays near the midplane resulting from $1-2 \mathrm{~cm}$ vertical shifts in the plasma column causing large fluctuations in measured $T_{\text {rad }}$.

Large fluctuations in EBW MC efficiency were observed on CDX-U (vertical grey arrows in Fig. 1(a)) and, while these were fairly strongly correlated with $L_{n}$ fluctuations at the MC layer, GENRAY [7] ray tracing calculations (Fig. 1(b)) indicate that vertical plasma oscillations of only $0.3 \mathrm{~cm}$ could account for oscillations in $T_{r a d}$ of $20-80 \mathrm{eV}$, or about half the observed $T_{\text {rad }}$ fluctuation. Detailed analysis of the CDX-U EBW MC experiments is presented elsewhere [8]. Since the NSTX plasma is much larger and better controlled than CDX-U, fluctuations in EBW emission due to refraction on NSTX are expected to be considerably smaller. Initial studies of EBW emission during NSTX plasmas showed $\square T_{\text {rad }} / T_{\text {rad }} \sim 20 \%$, confirming this expectation. These initial EBW emission measurements also indicated MC efficiency $<5 \%$ for L-mode discharges and $~ 15 \%$ during $\mathrm{H}$-modes, consistent with theoretical calculations using the measured $L_{\mathrm{n}}$ at the MC layer [9].

(a)

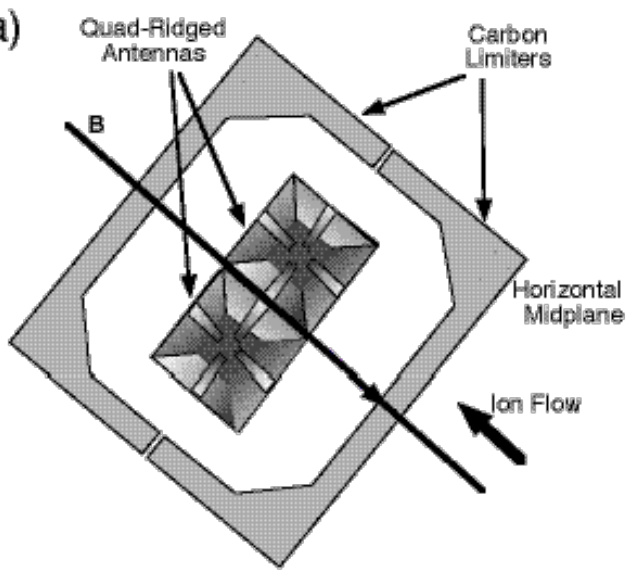

(b)

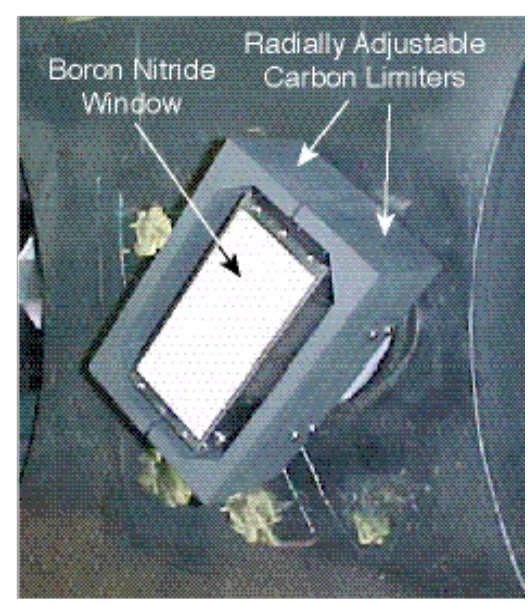

Looking outwards from NSTX center post

Figure 2. (a) Schematic diagram showing the layout of the X-mode EBW antenna installed on NSTX. Two carbon limiters surround a pair of quad-ridged antennas used for X-mode EBW radiometry and O-mode reflectometry. (b) Photograph of the antenna installed near the mid-plane of NSTX.

Recently, EBW MC experiments on NSTX, that use the HHFW antenna limiters to steepen $L_{n}$ at the MC layer, have demonstrated 40-50\% EBW MC [10]. The maximum MC efficiency was limited by the connection length between the antenna limiters which 
constrained the shortest achievable $L_{n}$ at the MC layer to $\sim 7 \mathrm{~mm}$. An X-mode EBW antenna with a local limiter calculated to achieve $L_{n} \sim 3 \mathrm{~mm}$ has been installed in NSTX (Fig. 2). An O-mode reflectometer integrated into the antenna will measure the local $L_{n}$ at the MC layer. This antenna is predicted to achieve better than $80 \% \mathrm{EBW}$ MC.

\section{EBW HEATING AND CURRENT DRIVE}

While the EBW MC studies on CDX-U and NSTX were motivated by the need to develop a fast electron temperature profile diagnostic for high $\square$, overdense plasmas, they also validate the MC physics for EBWH and EBWCD [5]. EBWH and EBWCD can help optimize the magnetic equilibrium and suppress deleterious MHD in ST plasmas that might otherwise prevent access to high $\square$ operation [11]. Deposition at r/a $>0.8$ may be required for MHD suppression in NSTX. Placing the EBW launcher well above or below the mid-plane on the low field side may have several benefits; large uni-directional $n_{\|}$ shifts, needed for efficient CD, can result even with an $n_{/ /} \sim 0$ launch [12], trapped particle effects that significantly reduce the EBWCD efficiency near the mid-plane can be minimized, and the launcher can be located where there is generally less competition for vacuum vessel access.

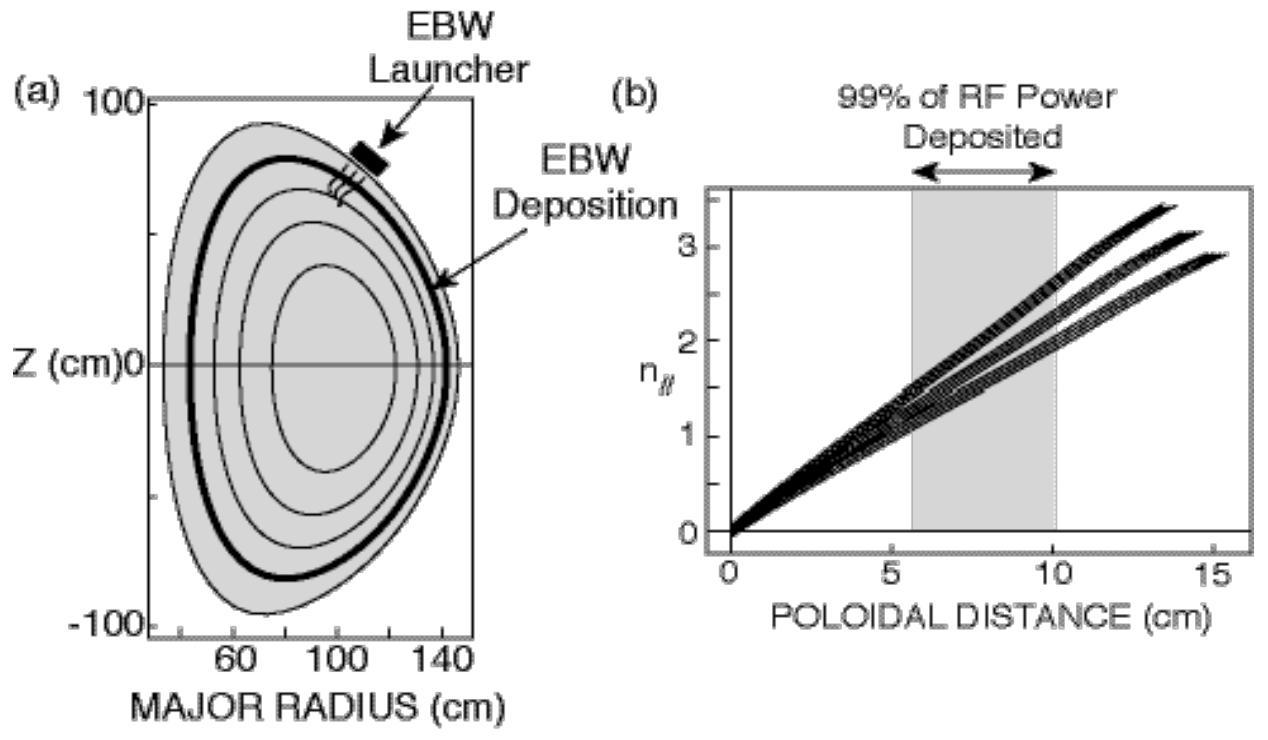

Figure 3. (a) GENRAY ray tracing calculation for $15 \mathrm{GHz}$ EBWs launched from a location at a poloidal angle 85 degrees above the mid-plane of NSTX for a $\square=30 \%$ plasma equilibrium. 12 rays are launched with $n_{/ /}$from -0.1 to +0.1 . EBW rays are projected on to a poloidal cross-section. (b) Plot of $n_{/ /}$versus poloidal projected distance along the ray show a significant shift in $n_{/ /}$within $5-10 \mathrm{~cm}$ of the plasma edge.

Figure 3(a) shows a GENRAY [7] calculation for a bundle of $15 \mathrm{GHz}$ EBW rays launched from 85 degrees above the mid-plane with a range of $n_{/ /}$between -0.1 and +0.1 . Figure 3(b) shows the significant $n_{/ /}$upshift that occurs during the first $5-10 \mathrm{~cm}$ the rays travel into the plasma. $99 \%$ of the EBW power is deposited at the Doppler-shifted second harmonic resonance within $6-10 \mathrm{~cm}$ from the plasma edge, shown by the thickened flux surface line in Fig. 3(a) and the grey shaded region in Fig. 3(b).

Modeling of the EBWCD was performed with the CQL3D bounce-averaged FokkerPlanck code [13] for the case shown in Fig. 3. CQL3D results for $1 \mathrm{MW}$ of launched EBW power are shown in Fig. 4. The EBW power is locally deposited near r/a $=0.8$ (Fig. 4(a)) and the resulting CD profile is shown in Fig. 4(b). The CD efficiency for this case is 0.06 $\mathrm{A} / \mathrm{W}$, assuming $100 \% \mathrm{MC}$ between the injected RF power and the EBW. Since $\mathrm{T}_{\mathrm{e}}=0.6$ $\mathrm{keV}$ and $\mathrm{n}_{\mathrm{e}}=1.6 \times 10^{19} \mathrm{~m}^{-3}$ at the CD location which has a major radius of $1 \mathrm{~m}$, this 
corresponds to a dimensionless current drive efficiency, $\square_{\mathrm{ec}}=0.53$ [14]. This is about three times the value of $\bigsqcup_{c c}$ obtained with the same plasma with $C D$ at $r / a=0.8$ near the midplane, is similar to the value obtained for EBWCD near the magnetic axis [15] and is about 2-3 times the $\square_{c c}$ for ECCD in DIII-D [16].

The EBW deposition profile and CD efficiency can be modified by changes in the density and temperature profile, a sensitivity study is being conducted to investigate this and an EBW launcher design is being developed that will allow control of $n_{/ /}$and the polarization of the electromagnetic launch wave for optimum coupling to the EBW. A single steerable mirror launcher combined with a rotatable reflective grating polarizer is being considered, since it provides the greatest flexibility for optimizing EBW coupling and control of the EBW power deposition. The launch frequency that provides the widest radial access to NSTX, which typically operates at 0.35 to $0.45 \mathrm{~T}$, is about $15 \mathrm{GHz}$. Presently, no high power RF sources with pulse durations of about $1 \mathrm{~s}$ exist at this frequency. MIT has proposed the development of an $800 \mathrm{~kW} 15 \mathrm{GHz}$ gyrotron tube, a $3 \mathrm{MW}$ EBW system using this tube is being considered for NSTX to assist non-inductive plasma startup, current ramp up, and to provide local electron heating and CD in high $\square$ NSTX plasmas.

\section{ACKNOWLEDGMENTS}

This work is supported by US Department of Energy (DoE) contract nos. DE-AC02-76CH03073, DE-FG02-

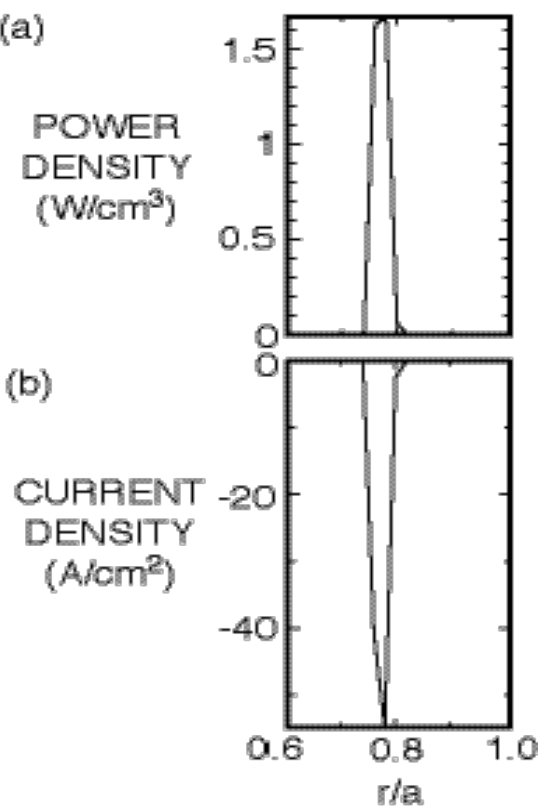

Figure 4. (a) The EBW power deposition profile and (b) EBWCD current density profile for the case in Fig. 3 for $1 \mathrm{MW}$ of RF power.

91ER-54109 and DE-FG02-99ER-54521 and by a DoE grant which is part of a program to encourage innovations in magnetic fusion energy diagnostic systems.

\section{REFERENCES}

[1] Menard, J., et al., Phys. Plasmas, 6, 2002-8 (1999).

[2] Ono, M., et al., Proc. $17^{\text {th }}$ IAEA Fus. Energy Conf. (IAEA, Vienna, 1999), 3, p. 1135.

[3] Preinhaelter, J., and Kopécky, V., J. Plasma Phys. 10, 1-12 (1973).

[4] Ram, A.K., and Schultz, S.D., Phys. Plasmas 7, 4084-4094 (2000).

[5] Ram, A.K., Bers, A., and Lashmore-Davies, C.N., Phys. Plasmas 9, 409-418 (2002).

[6] Jones, B., et al., Phys. Rev. Lett., 90, 165001 (2003).

[7] Smirnov, A.P., and Harvey, R.W., Bull. Am. Phys. Soc. 40, 1837 (1995).

[8] Jones, B., PhD. Thesis, Princeton University (2002).

[9] Taylor, G., et al., Phys. Plasmas, 9, 167-170 (2002).

[10] Taylor, G., et al., Phys. Plasmas, 10, 1395-1401 (2003).

[11] Efthimion, P.C., et al., "Applications of Electron Bernstein Wave Heating and Curent Drive in High $\square$ Plasmas”, Paper IAEA-CN-94/EX/P2-12, 19 ${ }^{\text {th }}$ IAEA Fus. Energy Conf., Lyon, France, October 2002.

[12] Forest, C.B., et al., Phys. Plasmas, 7, 1352-1355 (2000).

[13] Harvey, R.W., and McCoy, M.G., Proc. IAEA. Com. on Advances in Simulation and Modeling of Thermonuclear Plasmas, Montreal, Quebec (IAEA, Vienna, 1993) p. 489.

[14] Luce, T.C., et al., Phys. Rev. Lett., 83, 4550-4553 (1999).

[15] Taylor, G., et al., "Mode-Converted Electron Bernstein Wave Emission Research on CDX-U and NSTX", Proc. 12 $2^{\text {th }}$ Joint Workshop on ECE and ECRH, edited by G. Giruzzi, World Scientific, Singapore, 2003, pp. 151-160.

[16] Petty, C.C., et al., "Electron Cyclotron Wave Experiments on DIII-D”, Proc. 14 ${ }^{\text {th }}$ Topical Conference on Radio Frequency Power in Plasmas, edited by T.K. Mau and J. deGrassie, AIP Conf. Proc. 595, Melville, New York, 2001, pp. 275-281. 


\section{External Distribution}

Plasma Research Laboratory, Australian National University, Australia

Professor I.R. Jones, Flinders University, Australia

Professor João Canalle, Instituto de Fisica DEQ/IF - UERJ, Brazil

Mr. Gerson O. Ludwig, Instituto Nacional de Pesquisas, Brazil

Dr. P.H. Sakanaka, Instituto Fisica, Brazil

The Librarian, Culham Laboratory, England

Mrs. S.A. Hutchinson, JET Library, England

Professor M.N. Bussac, Ecole Polytechnique, France

Librarian, Max-Planck-Institut für Plasmaphysik, Germany

Jolan Moldvai, Reports Library, MTA KFKI-ATKI, Hungary

Dr. P. Kaw, Institute for Plasma Research, India

Ms. P.J. Pathak, Librarian, Insitute for Plasma Research, India

Ms. Clelia De Palo, Associazione EURATOM-ENEA, Italy

Dr. G. Grosso, Instituto di Fisica del Plasma, Italy

Librarian, Naka Fusion Research Establishment, JAERI, Japan

Library, Plasma Physics Laboratory, Kyoto University, Japan

Research Information Center, National Institute for Fusion Science, Japan

Dr. O. Mitarai, Kyushu Tokai University, Japan

Dr. Jiangang Li, Institute of Plasma Physics, Chinese Academy of Sciences, People's Republic of China

Professor Yuping Huo, School of Physical Science and Technology, People's Republic of China

Library, Academia Sinica, Institute of Plasma Physics, People's Republic of China

Librarian, Institute of Physics, Chinese Academy of Sciences, People's Republic of China

Dr. S. Mirnov, TRINITI, Troitsk, Russian Federation, Russia

Dr. V.S. Strelkov, Kurchatov Institute, Russian Federation, Russia

Professor Peter Lukac, Katedra Fyziky Plazmy MFF UK, Mlynska dolina F-2, Komenskeho Univerzita, SK-842 15 Bratislava, Slovakia

Dr. G.S. Lee, Korea Basic Science Institute, South Korea

Institute for Plasma Research, University of Maryland, USA

Librarian, Fusion Energy Division, Oak Ridge National Laboratory, USA

Librarian, Institute of Fusion Studies, University of Texas, USA

Librarian, Magnetic Fusion Program, Lawrence Livermore National Laboratory, USA

Library, General Atomics, USA

Plasma Physics Group, Fusion Energy Research Program, University of California at San Diego, USA

Plasma Physics Library, Columbia University, USA

Alkesh Punjabi, Center for Fusion Research and Training, Hampton University, USA

Dr. W.M. Stacey, Fusion Research Center, Georgia Institute of Technology, USA

Dr. John Willis, U.S. Department of Energy, Office of Fusion Energy Sciences, USA

Mr. Paul H. Wright, Indianapolis, Indiana, USA 
The Princeton Plasma Physics Laboratory is operated by Princeton University under contract with the U.S. Department of Energy.

\author{
Information Services \\ Princeton Plasma Physics Laboratory \\ P.O. Box 451 \\ Princeton, NJ 08543
}

Phone: 609-243-2750

Fax: 609-243-2751

e-mail: pppl_info@pppl.gov

Internet Address: http://www.pppl.gov 